Article

\title{
Beyond the Certification Badge-How Infrastructure Sustainability Rating Tools Impact on Individual, Organizational, and Industry Practice
}

\author{
Kerry Griffiths ${ }^{1, *(\mathbb{D})}$, Carol Boyle ${ }^{2}$ and Theunis F. P. Henning ${ }^{1}$ \\ 1 Department of Civil and Environmental Engineering, University of Auckland, Auckland 1142, New \\ Zealand; t.henning@auckland.ac.nz \\ 2 Faculty of Science Engineering \& Built Environment, Deakin University, Geelong Waurn Ponds Campus, \\ Geelong, VIC 3220, Australia; carol.boyle@deakin.edu.au \\ * Correspondence: kerry.griffiths@xtra.co.nz; Tel.: +64-(0)-29-496-3861
}

Received: 5 February 2018; Accepted: 29 March 2018; Published: 31 March 2018

\begin{abstract}
Sustainability consideration in designing, constructing, and operating civil infrastructure requires substantive action and yet progress is slow. This research examines the impact third-party infrastructure sustainability rating tools-specifically CEEQUAL, Envision, Greenroads, and Infrastructure Sustainability - have beyond individual project certification and considers their role in driving wider industry change. In this empirical study, engineering and sustainability professionals $(n=63)$ assess and describe their experience in using rating tools outside of formal certification and also the impact of tool use on their own practice and the practices of their home organizations. The study found that 77\% of experienced users and 59\% of infrastructure owners used the tools for purposes other than formal project certification. The research attests that rating tool use and indeed their very existence has a strong influence on sustainability awareness and practice within the infrastructure industry, providing interpretation of sustainability matters in ways that resonate with industry norms. The rating tools impact on individuals and their professional and personal practice, on the policies and practices of infrastructure-related organizations, and more widely on other industry stakeholders. The findings can be used to increase the value gained from sustainability rating tool use and to better understand the role such tools play in creating cultural change within the industry.
\end{abstract}

Keywords: sustainable infrastructure; rating tools; culture change; engineering profession

\section{Introduction}

Sustainability rating tools such as Envision and CEEQUAL are intended to improve the environmental, social, and economic outcomes from the construction and operation of physical infrastructure. Every year trillions of dollars are spent on retrofitting existing physical infrastructure and building new physical infrastructure [1], with increased spending needed to address past underinvestment and cope with predicted population growth (i.e., an expected global population of 9 billion by 2050). Physical infrastructure is critical to society, providing families, businesses, industries, and whole communities with access to shelter, water, energy, transport, communication, and sanitation [2,3], and how such infrastructure functions is critical to making progress in terms of sustainability. Decisions related to infrastructure development have a significant impact on our ability to live sustainably - whether through limiting air and water pollution, promoting resource efficiency and integrated urban development, or ensuring access to zero- or low-carbon energy and mobility services [4]. For example, the globalization of Western infrastructure using current technologies would 
result in approximately $350 \mathrm{Gt} \mathrm{CO}_{2}$ from materials production-about $35-60 \%$ of the remaining carbon budget available until 2050 if the global temperature increase is to be limited to $2{ }^{\circ} \mathrm{C}$ [5]. In the United Kingdom alone, the built environment contributes nearly $50 \%$ of all carbon emissions and $33 \%$ of landfill waste and consumes $13 \%$ of raw material and $50 \%$ of water [6]. Badly designed infrastructure puts pressure on land and natural resources and impacts negatively on the community and the natural and built environments $[7,8]$. If we do not invest in sustainable infrastructure, we will exacerbate rather than resolve current environmental and social challenges and lock future generations into costly legacy systems that do not meet their needs [9].

The infrastructure industry needs to adopt new thinking, practices, and approaches, and designing and building for sustainability need to become the norm. Sustainability rating tools for civil infrastructure are one response from industry to bridging the current gap, and in this study, we investigate the impact of the infrastructure sustainability rating tools beyond individual projects, by analyzing non-certified tool use and examining how tool use influences individual and organizational practice.

\subsection{Background on the Rating Tools}

The use of sustainability rating tools in the built environment began in the 1990s and 2000s [10], with building rating tools such as BREEAM (UK), LEED (USA), and Green Star (Australia and New Zealand) now recognized for contributing strongly to the green building revolution [11-13]. In the early 2000s, studies highlighted the lack of similar tools for infrastructure beyond buildings (e.g., road, rail, energy, and water systems) [14-16]. In the United Kingdom, the civil infrastructure industry, led by the Institution of Civil Engineers, launched the CEEQUAL infrastructure rating tool in 2003 [17]. Following on from CEEQUAL, collaborative industry initiatives established Greenroads [18] and Envision [19] in the United States and the Infrastructure Sustainability tool [20] in Australia. These four rating systems are growing in use in the infrastructure marketplace and multiple case studies of projects certified under the schemes are available [21-24].

Infrastructure sustainability rating tools function in a similar way to their building counterparts and are used to assess and certify project and asset performance against a range of sustainability criteria including resource use, ecology, stakeholder involvement, community impacts, climate change and resilience, land use, and urban design. These tools are usually specified by infrastructure owners, for example, transport agencies and territorial authorities, and applied to capital projects or infrastructure assets by project teams (design and construction engineers and sustainability advisors) [26]. By the end of 2016, CEEQUAL had been used to certify more than 360 projects with a further 250 registered for certification; Envision had been used to certify 25 projects with a further 37 registered for certification; Infrastructure Sustainability had been used to certify 28 projects with a further 67 registered for certification; and Greenroads had been used to certify 37 projects with a further 30 registered for certification (Griffiths, unpublished).

The strengths and weaknesses of infrastructure sustainability rating tools have been identified in a number of studies $[25,27-30]$ and are summarized in Table 1 . These factors signal the appeal of rating tools as well as the challenges often identified with their use. As noted by Pearce and Vanegas [31] in regard to the building rating tools, the "real world utility" of rating tools may in fact be one of the reasons these tools continue to grow in use despite their limitations. Bartke and Schwarze [32] suggest there is no perfect tool and that the best tool may be the one that achieves the trade-off required between adequately addressing sustainability principles and providing a scheme that is understood by and accessible to practitioners. 
Table 1. Sustainability Rating Tools—strengths and weaknesses.

\begin{tabular}{l}
\hline \multicolumn{1}{c}{ Strengths } \\
\hline Multi-dimensional and criteria-based, providing a common metric and language; \\
Mechanism for setting a third-party verified evidence-based standard; \\
Encourage infrastructure owners and project teams to strive for higher levels of sustainability performance; \\
Potentially lead to adoption of green practices into regulation and planning mechanisms, and minimum standards; \\
Make sustainability measurable and manageable; \\
Allow for clear communication of sustainability goals, efforts, and achievement; \\
Flexible framework allowing for innovation in design and construction solutions. \\
\hline \multicolumn{1}{c}{ Weaknesses } \\
\hline Simplification of a complex situation through a single rating 'score' with potential loss of visibility of underlying drivers; \\
Do not capture the entire scope of sustainable infrastructure actions, in particular social and economic issues; \\
Seeking to minimize 'unsustainability' rather than create something sustainable; \\
Difficult to cover the full range of infrastructure projects, which differ in scale, character, and location; \\
Checklist approach does little to promote an integrated design strategy; \\
Tendency to 'points chase' through mandatory requirements and rating thresholds, and can guide rather than be guided \\
by design; \\
Less suitable for using with stakeholders in decision-making about infrastructure options. \\
\hline
\end{tabular}

\subsection{State of Progress_Infrastructure Industry}

Over the last few decades, alongside the development of sustainable science, technologies, materials, and assessment and measurement tools, the need for the infrastructure industry to take a stronger role in delivering on the promise of sustainable development has been highlighted in the research and within the engineering profession [3,33,34]. However, progress in sustainable infrastructure is slow. Studies that investigated barriers and challenges to sustainable design and construction have highlighted limited sustainability knowledge and understanding, uncertainty and unfamiliarity with sustainable materials and technologies, and a tendency to maintain current practices $[13,35,36]$. Chong et al.'s study of sustainability in the construction industry [34] identified a strong level of conservatism in the civil engineering sector and recommended broadening the knowledge in sustainability, making sustainability more relevant and necessary to the professionals and their organizations, and providing platforms for communication and sharing ideas. In 2011, Willetts et al. [37] found that, while sustainability is acknowledged as important to engineering firms, the engineering consultancy sector was behind other sectors such as mining, oil and gas, and financial services in terms of sustainability performance and reporting. Vaillancourt et al. [38] (p. 3189) suggest that civil engineers "need to change from technicians to agents which promote sustainability, specifically sustainable infrastructure." In this study, we investigate how infrastructure sustainability rating tools can create change within the civil infrastructure sector, and in particular consider the extent to which tools contribute beyond the formal certification of individual projects.

\subsection{Change, Development, and the Spreading of Ideas}

In order to examine the role the rating tools play in industry change, an understanding of change processes and the factors that influence change is needed. In her book "Psychology for a Better World" [39], Harré explores how sustainability ideas and actions are encouraged and adopted. She emphasizes the importance of identity, culture, and social norms in inspiring people to get involved and become part of a community. According to Harré, people are inclined "to reproduce what they see as 'normal' in any given situation" [39] (p. 41) and therefore the more sustainable choices and behaviors are modelled and normalized, the more likely they are to be repeated. A person's identity is reflected in how they think about themselves, how they see others, who they connect with, and ultimately in how they behave. Relatable role models, whether individuals, projects, or organizations, are therefore key influencers in building a sustainability culture. Harré's emphasis on the importance of like-minded communities in driving sustainability action reflects Lave and Wenger's seminal work on learning as a social activity [40], which attested the importance of communities of practice in 
acquiring new knowledge and skills. Such communities are characterized by mutual engagement focused on advancing practice, and the existence of shared resources-tools, methods, case studies, and stories-which support action and on-going learning. When we try to introduce new ideas that have longer term benefits, as is often the case with sustainability and infrastructure issues, change is usually slow. Rogers [41] emphasizes the importance in such cases of stressing the positive advantages of change, of using champions and role models, and of changing social norms. Similar to Harré, he highlights the value of peer support, education, and active peer networks. In this study, we examine the extent to which the rating tools provide these aspects—sense of identity, community of practice, tools and resources-which are so important in the change process.

Many of the factors related to adopting new behaviors are also present in Prochaska's Transtheoretical Model of Behavior Change (TTM) [42]. The TTM includes a 'processes of change' construct which outlines five experiential and five behavioral processes (Table 2). While the TTM's 'stages of readiness for change' construct suggests when shifts in attitudes, intentions, and behaviors occur, the processes of change suggest how these shifts occur and identify systems and structures for change creation. These processes of change provide insight into how the rating tools might support behavior change with the engineering and wider infrastructure industry.

Table 2. Transtheoretical Model of Behavior Change-Processes of Change [43-45].

\begin{tabular}{ll}
\hline Experiential Processes of Change \\
\hline Consciousness raising & $\begin{array}{l}\text { Increasing awareness via information, education, and personal feedback about a problem } \\
\text { behavior and potential solution. }\end{array}$ \\
\hline Dramatic relief & $\begin{array}{l}\text { Experiencing negative and positive emotions regarding the behavior/change; feeling fear, } \\
\text { anxiety, or worry about failure to change, or feeling inspiration and hope about } \\
\text { successful change. }\end{array}$ \\
\hline $\begin{array}{l}\text { Environmental } \\
\text { reevaluation }\end{array}$ & Assessing impact on others of your behavior and possible change. \\
\hline Self-reevaluation & $\begin{array}{l}\text { Realizing that the behavioral change is important to one's personal identity, happiness, } \\
\text { success, and/or values. }\end{array}$ \\
\hline Social liberation & $\begin{array}{l}\text { Empowering individuals to change behavior through providing choices and resources; societal } \\
\text { support for the behavior; realizing that social norms are changing to support the new behavior. }\end{array}$ \\
\hline Behavioral Processes of Change \\
\hline Self-liberation & $\begin{array}{l}\text { Making a firm commitment to act; believing in one's ability to change and making } \\
\text { commitments and recommitments to act. }\end{array}$ \\
\hline Helping relationships & $\begin{array}{l}\text { Seeking and using social support to make and sustain change; interacting with people who are } \\
\text { supportive of the new behavior. }\end{array}$ \\
\hline Counter conditioning & \begin{tabular}{l} 
Substituting new behavior ways of acting, speaking, and thinking for the old behaviors. \\
\hline $\begin{array}{l}\text { Reinforcement } \\
\text { management }\end{array}$
\end{tabular}$\quad \begin{array}{l}\text { Increasing rewards for new behaviors-from self and by others; decreasing rewards for old } \\
\text { behaviors. }\end{array}$ \\
\hline Stimulus control & $\begin{array}{l}\text { Restructuring the environment by introducing reminders and cues to engage in the new } \\
\text { behaviors; remove reminders and cues for the old behaviors. }\end{array}$ \\
\hline
\end{tabular}

Complexity theory $[46,47]$ adds further insight when the desired change is within a multi-faceted and multi-layered system, as is the case with infrastructure development. Complexity theory suggests that even small changes at the individual, organizational, and industry levels can have far reaching impacts. Distributed and often uncoordinated changes can allow a system to adapt and learn, as long as feedback occurs and there is capacity to respond. The power of small interventions to contribute to the system-level change needed for on-going survival and growth should not be underestimated [48]. The infrastructure sustainability rating tools are potentially such a case in point.

\subsection{Study Objective}

While studies into infrastructure sustainability rating tools are often directed at the adequacy of tool design, or the outcomes achieved at the project level through rating and certification, the impact 
of using infrastructure sustainability rating tools potentially goes beyond the impact on individual rated projects. The nature of behavior change and idea diffusion suggests that change is brought about by a combination of factors in an on-going process of adaptation and learning. In the building industry, the use of sustainability rating tools has been identified as contributing to the "greening" of industry knowledge, practices, and products [11-13]. These factors raise the question of the broader contribution made by the infrastructure sustainability rating tools. To that end, the objectives of this study were to:

- Analyze 'non-certified' rating tool use (i.e., beyond formal certification);

- Examine the influence of rating tool use on practice beyond the rated project-for individuals and organizations;

- Investigate how these 'beyond certification' practices and influences contribute to the much needed change within the infrastructure development sector.

The study tested whether there is evidence that the tools, as suggested by CEEQUAL [49], "create a climate of sustainability awareness—and of continuous improvement—in the profession and industry."

\section{Study Method}

Data on the influence of the infrastructure sustainability rating tools was collected using semi-structured interviews with rating tool users and infrastructure owners. Users of the third-party verified rating tools-CEEQUAL, Envision, Greenroads, and Infrastructure Sustainability-were selected for the interviews as these tools are increasingly used in the real world to assess and certify infrastructure projects. The interviews were guided by a mix of open, yes/no, and rated questions, which allowed for quantitative and qualitative responses, and were carried out either face-to-face or via skype. The questions for this study-tested first with a small sample of tool users-examined non-certified use of the rating tools by infrastructure owners and experienced users, and the impact of project-related tool use on individual practice and organizational practices (see Appendix A for question details). These interviews were part of a broader $\mathrm{PhD}$ research project investigating sustainability outcomes and rating tool use.

The data was collected from 63 research participants (Table 3) who had experience in using, or specifying use of, at least one of the four rating tools and were collectively involved in more than 480 rated projects. The sample size was selected to include a mix of roles, geographies, and user experience levels and to reflect the relative level of tool use across the four tools. Interviewees were identified through the researcher's professional networks and open invitations sent by tool developers to their networks. Participants were identified at different levels of experience in rating tool use: Super User (10+ certifications; across multiple projects), High ( $>5$ small or medium certified projects OR $>2$ large certified projects; OR 2 or more mega projects), Medium (4-5 small to medium certified projects OR 2 large projects OR 1 mega projects), and Low (1-3 small or medium certified projects OR 1 large project). The tool users included 17 employees from construction firms, 22 employees from design firms, five employees from project organizations, and three from small consultancy firms. The infrastructure owners included employees from nine transport authorities, five local government organizations, two airports, and one urban development agency.

Table 3. Characteristics of Research Participants $(n=63)$.

\begin{tabular}{cccc}
\hline $\begin{array}{c}\text { Role and Number of } \\
\text { Participants }\end{array}$ & $\begin{array}{c}\text { Geographic Spread of } \\
\text { Participants }\end{array}$ & $\begin{array}{c}\text { Rating Tool Used } \\
\text { by Participants }\end{array}$ & $\begin{array}{c}\text { Tool Experience of } \\
\text { Participants }\end{array}$ \\
\hline & United Kingdom $\times 28$ & CEEQUAL $\times 28$ & Super users $\times 6$ \\
Infrastructure owners & United States $\times 16$ & High $\times 15$ \\
$\times 17$ & Australia $\times 15$ & Envision $\times 8$ & Mreenroads $\times 10$ \\
Experienced tool users & New Zealand $\times 2$ & Canada $\times 1$ & Low $\times 25$ \\
$\times 46$ & Norway $\times 1$ & Infrastructure Sustainability $\times 17$ & \\
& & & \\
\hline
\end{tabular}


Analysis of the participant responses included statistical analysis of the quantitative data and coding analysis of the qualitative data, which was categorized using the NVIVO analysis software, and applied the constant comparative model used by Boeije [50] to identify data groupings and themes more or less inductively, namely categorizing, coding, delineating categories, and connecting them (see Appendix A for codebook example). Coding was completed by the researcher who undertook all the interviews. Results from the interviews included the coded data and graphics to show themes and trends, as well as participant quotes, which show the deeper examination of issues available through interview-based research [36]. In the findings section, selected participant quotes are presented to provide added, more nuanced insight into the responses behind the quantitative and grouped results. In the discussion section, the change processes and behavior influencing factors outlined above are referenced to demonstrate the link between the study findings and the role of the rating tools in creating and supporting culture change within the infrastructure industry.

\section{Study Findings}

\subsection{How Are Rating Tools Used outside of the Cerification Process?}

One of the ways to understand the wider impacts of sustainability rating tools is to examine the extent to which they are used outside of the projects where certification is required. To that end, the infrastructure owners and tool users were asked whether they used the tools in "non-certified" ways and, if they did, what they used them for. The study showed that $77 \%$ of the experienced users and $59 \%$ of infrastructure owners used the tools in non-certified ways. Figure 1 summarizes the different activities identified, with the most common use being to utilize the tools (and their supporting documentation) as a general guide or framework on sustainability and infrastructure. A number of participants used the tools to undertake informal project assessments without going through the certification process, with one infrastructure organization making significant non-certified use of Envision, and another organization requiring project teams to undertake a self-assessment on lower value capital projects using the Infrastructure Sustainability tool. Some participants referenced the tool content to incorporate sustainability thinking during feasibility and planning phases of a project, to inform organizational sustainability strategy, policies, and management systems for infrastructure development, to assess and inform design approaches, or to assist with sustainability training.

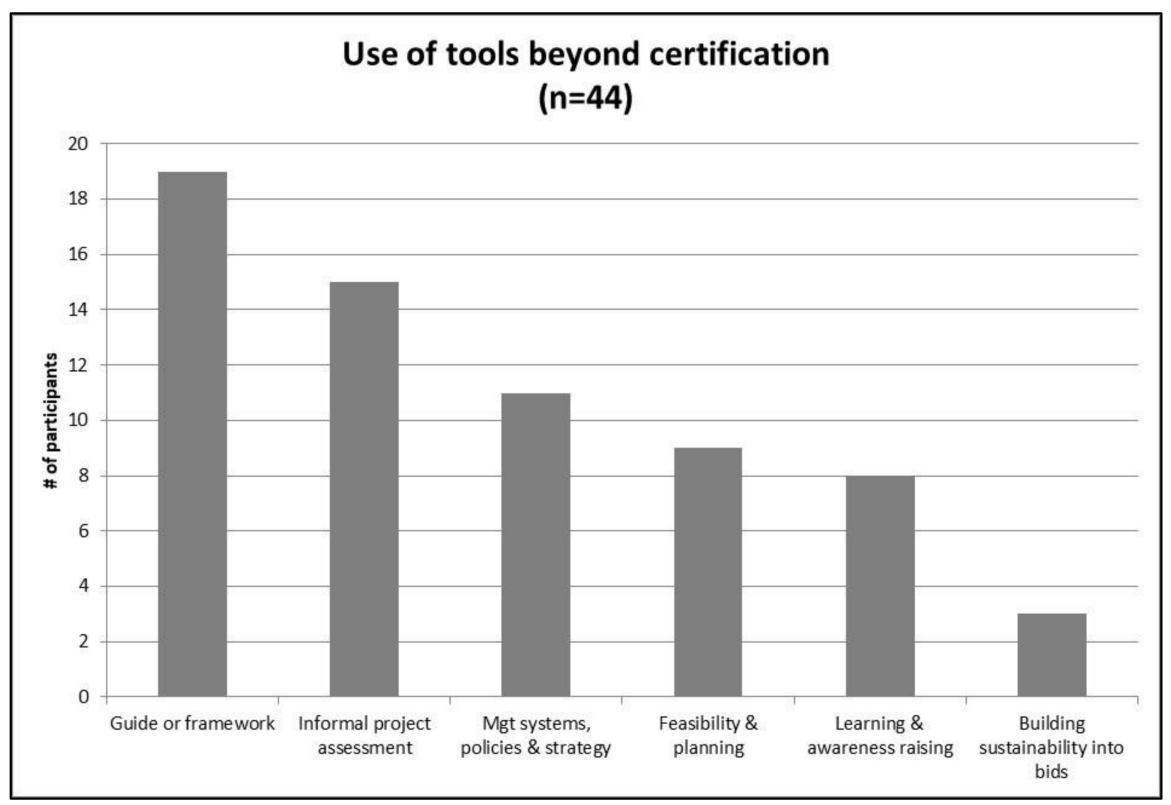

Figure 1. Reasons for using tools in non-certified ways (owners and users). 
I do look to add in some of those best practice elements. Things like water footprinting's something that not many clients are looking at and is within CEEQUAL.

If you're doing a program of projects or maybe a smaller project, you might just want to actually say, use the CEEQUAL methodology but not necessarily feel that you want to go the whole hog and have it certified, because it still brings a good degree of rigor into your thinking, your thought process.

I worked in a regional capacity and we were developing some regional sustainability strategies. We used the CEEQUAL tool as a framework and a bit of a standard for best practice.

On this project, we've actually developed an option evaluation tool, very simple. There's nothing else to help us evaluate options in terms of sustainability so we developed one. It's simply based on the CEEQUAL headings and some of the questions.

We actually have put our best effort to use Envision as much as possible for all projects, or as many projects as possible, and from their planning and design phase. So far, around 150 projects have been rated [but not verified] using Envision.

We're using that [Greenroads] as an education tool because when it's all put into one package, ... you can go over those issues really quickly instead of doing it hit and miss, here and there.

\subsection{How Does Rating Tool Use Influence an Individual's Future Practice?}

The experienced user interviews explored the extent to which the interviewee's own practice changed as a result of using the sustainability rating tools for project certification. The majority of users $(77 \% ; n=44)$ rated the tools as having a strong or extremely strong influence on their own practice, citing enhanced knowledge and understanding of sustainability, in particular a broadening of knowledge beyond the immediate environmental impact areas, as well as enhanced confidence in working with others on sustainability issues, more recognition by others, and the value of being part of an identified community of practice (Figure 2). A few participants also noted the spill-over effect into their practices outside of work (e.g., in undertaking home renovations). Those respondents who rated tool influence on their own practice as low, all had strong existing sustainability or environmental knowledge.

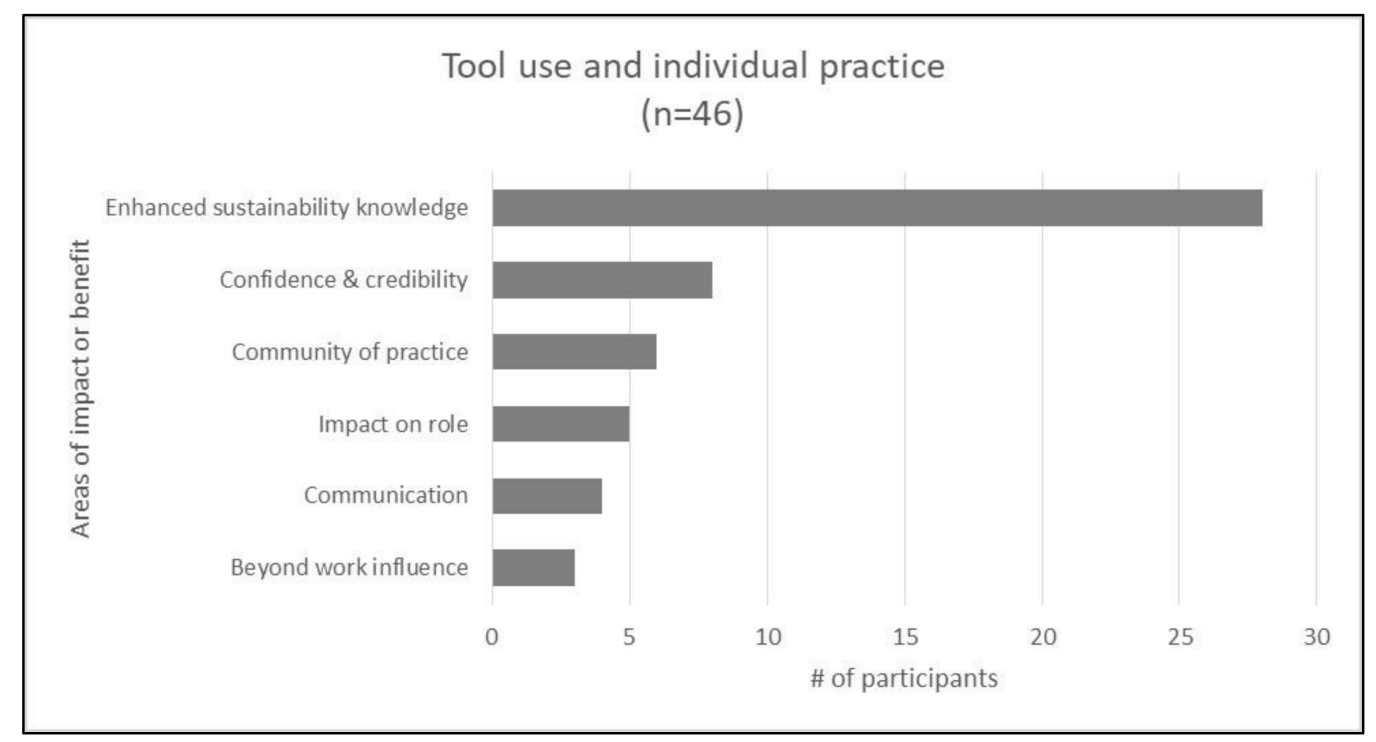

Figure 2. Impact of tool use on individual practice.

It's raised my awareness in a lot of specific areas. You know, like biodiversity and ecology and water footprinting. That was something I really didn't know a lot about. 
Quite often I go back to the manual and then even if it's not a CEEQUAL project but another project I'm working on, I would go back and look at certain questions and how I can challenge the project team or the design team.

As an engineer, the IS (Infrastructure Sustainability) tool gives me a structure to work with. The IS tool is an industry-wide accepted framework which helps me to deliver sustainability.

I think CEEQUAL for me gives me a little bit of confidence. I'm working fairly remotely down here ... and I am not maybe as in touch with sustainability things that somebody who is working on [a high profile urban project].

Prior to my involvement with Envision, my colleagues would never even have brought me in on almost any infrastructure project. Now me and my core team, we're the company experts and well known as that across the company.

I do think though of the tool and having it connect us with other like-minded sustainable focused engineers has allowed us to think creatively and adopt some other principles from other projects.

I think the biggest one is just the way I communicate; the way I communicate with my clients and with the public about sustainability. Just having that language has changed the way I do that a lot.

I just went through a home renovation and implemented many of the same sustainable concepts that are in the system. I also tended to look for ways to improve the community in which I live and the thought process behind that is based on all the credits like in the quality of life category for Envision.

\subsection{How Do Rating Tools Influence Organizational Practice?}

The level of influence of the rating tools on organizational practice varied amongst interviewees, with the overall impacts seen as less strong than the influence on individual practice. Infrastructure owners-those who usually specify tool use on capital projects-varied in the degree to which the rating tools were embedded in their organization's policies and practices. Forty-seven percent of the infrastructure owners interviewed worked in organizations that specified rating tool use in their sustainability policies or management systems, while others made decisions on tool use on a case by case or more ad hoc basis. While these findings illustrate the 'formal use' of the tools by asset owners, of more interest here is how tool use has influenced the organizations of those who used the tools on projects—sustainability advisors, environmental managers, project managers, and design and construction engineers. Tool user experience of how much the tools influenced their home organization's practices also varied (Table 4). The most common area of influence related to increasing organizational knowledge and understanding of sustainability, with some impacts on internal sustainability management systems and policies, and on client offerings. When analyzed by firm type, the influence was stronger for the construction firms than for design firms, and this finding is reflected in the mix of participant quotes below.

Table 4. Tool influence on home organization's practices-1 (no influence) to 5 (extremely influential).

\begin{tabular}{cccccc}
\hline & Min & Max & $\begin{array}{c}\text { Moderately } \\
\text { Influential }\end{array}$ & $\begin{array}{c}\text { Very } \\
\text { Influential }\end{array}$ & $\begin{array}{c}\text { Extremely } \\
\text { Influential }\end{array}$ \\
\hline All respondents $(n=39)$ & 1 & 5 & 10 & 9 & 5 \\
Construction $(n=15)$ & 2 & 5 & 4 & 6 & 2 \\
Design $(n=19)$ & 1 & 5 & 6 & 2 & 2 \\
Other $(n=5)$ & 1 & 5 & 0 & 1 & 1 \\
\hline
\end{tabular}

A number of construction companies had established strong policies, changed project environmental management systems, and undertaken extensive organizational training in 
sustainability. Generally, design firms trained specialist staff to undertake assessments but were less likely to drive significant change at the organizational level as a result of rating tool use on projects (with a couple of exceptions). Nearly $50 \%$ of designers interviewed perceived no influence or a slight influence of the rating tools on their organizational practices.

We're using the manual and the pre-assessment sheet as a learning aid and that does raise awareness across the business ... we've got our environmental documents and procedures in there. Those have been improved as a result of the CEEQUAL manual. And going away from the environmental stuff, it's raising awareness of the social and economic impacts.

From the organizational perspective, we are now moving much more onto embedding these questions into individual project management products. So even for like small scale projects where we wouldn't necessarily go for an external assessment.... There are definitely elements in the manual, in the questions which we can then take out and embed into other templates and forms.

My position [Sustainability Director] is a year and a half old and this past year we've got a few projects certified and going into 2017 we've got probably double that in the line to get certified. So, it's trending upwards. We currently have 70 Envision SPs (Sustainability Professionals).

Each project team is its own little kingdom. The ones that have used it that's influenced greatly. The ones that haven't used it, it hasn't really influenced much at all.... so it's not like it's affected the whole organization; it's affected the various project teams.

Still very slow. The majority of our staff haven't used the tool; about 12-20 people exposed to the tool across the Australian business. ... Not yet standard practices that we do what is in IS-many projects still driven by a lowest price/business-as-usual approach.

\subsection{How Do the Rating Tools Impact on the Wider Industry?}

As well as the influences at the individual and the organizational practice levels, some research participants identified the influence of the rating tools through the supply chain and at a wider industry level, suggesting that the tools were driving a change within industry and that learning was progressing from current to future projects. These findings on the wider influence, indicated in the quotes below, surfaced unprompted in discussion with interviewees about the use and value of the rating tools generally.

Signal to the market for sustainability products and services (the rating tool provides some traction along the supply chain).

It creates a way for the whole industry to improve instead of everybody moving in different directions and not really talking the same language.

Think we are right in the middle of a step change now throughout the industry.

On the [project name] a number of people were IS accredited professionals including the Design Manager and a number of engineers. They are the same teams that will work on future projects-it pushed the team and the industry forward.

I think in the wider marketplace, the fact that these tools exist in and of themselves-that changes the territory. So, you may not necessarily use it, but the fact that it exists gives you an entrée to discussion, an entrée into raising some of the [sustainability] agenda. 


\section{Discussion}

The findings show that the rating tools are used extensively beyond formal project certification. They clearly provide a much needed guide for considering sustainability in infrastructure development generally, as well as a useful framework for informal assessments or ratings. As the 'social liberation' process of change in Prochaska's TTM highlights, access to a structured framework with choices (sustainability categories and areas for action) and resources (training and manuals) empowers individuals to adopt new behaviors. The structured checklist of options and performance levels provided by the rating tools models familiar engineering behavior $[51,52]$ and links sustainability with the engineering identity [39], as reflected in this quote: You have a one-page checklist and you'd be surprised how motivating a checklist with points are [sic] to an engineer. As identified by Harré, the modelling of behaviors and the links with identity are important aspects in normalizing sustainable practices.

The responses from research participants overwhelmingly demonstrate that the rating tools address the lack of knowledge and understanding of the sustainability agenda identified in the engineering profession and infrastructure industry through increasing and broadening sustainability knowledge at the individual level and providing a learning aid for sustainability training and knowledge development at the organizational level. The common framework and language provided by the tools, the case studies, and exemplar projects and practices, and the peer network and support provided within the community of practice contribute to the development of new social norms and hence new ways of behaving and thinking within the industry, thus contributing to the creation of a sustainability culture [39]. The use of the rating tools beyond specific project certification-in particular through non-certified use and influence on individual practices-shows the tools as valuable mechanisms for supporting the change needed in the engineering profession and infrastructure industry. The study findings demonstrate how the tools serve as Prochaska's processes of change [42], including 'consciousness raising' through providing information and education, 'social liberation' through empowering individuals through providing choices and resources, 'helping relationships' through providing peer support and peer networks with others wanting to advance the sustainable infrastructure agenda, and 'counter conditioning' by providing a common language and framework for substituting old practices and approaches with alternative more sustainable practices.

Roger's five strategies for accelerating the diffusion of preventive ideas and innovations [41] are also reflected in the research participants' experiences. The study findings confirm that tool users experienced positive benefits in terms of their own knowledge and development, and their levels of confidence in implementing sustainability practices. The findings identified significant advantages of the rating tools beyond project certification, including enhancing project and asset management systems, developing sustainability decision-making frameworks, and allowing new conversations with colleagues and clients. Participants identified the tools as increasing the confidence of sustainability champions, providing opportunities for peer support and peer networks, and influencing industry norms on a wider scale. As one infrastructure owner noted on the value of the tools in supporting sustainability champions: There are some real champions who want to do the best they can on projects; the tool has enabled them to get traction.

These results related to confidence and individual champions are significant, as individual champions are known to play an important role in sustaining the dialogue within industry on new thinking and practice until more substantive change takes place and learning is firmly embedded into policy [53,54]. The study findings also identified that the tools facilitated peer support amongst practitioners and provided access to communities of practice-both important factors in positive behavior change and diffusion of new ideas $[39,41,43]$. By addressing many of the factors identified as important in change creation, the study findings attest that infrastructure sustainability rating tools accelerate the diffusion of sustainability knowledge and practice within the engineering profession and the infrastructure industry. As Figure 3 illustrates, tool users not only work to deliver rating certification on individual infrastructure projects, but their experience in using the rating tools influences their future practice, exposes them to communities of practices where on-going learning and sharing of 
practice takes place, and provides them with tools that can be applied in multiple ways to enhance sustainability outcomes and to progress the understanding and embedding of sustainability at the organizational level. As complexity theory suggests [46], many such users, each with a little knowledge individually, have the potential to produce outcomes that collectively shift the industry within which they operate. The study participants perceived such industry changes taking place and attributed these changes at least in part to the existence and influence of the rating tools.

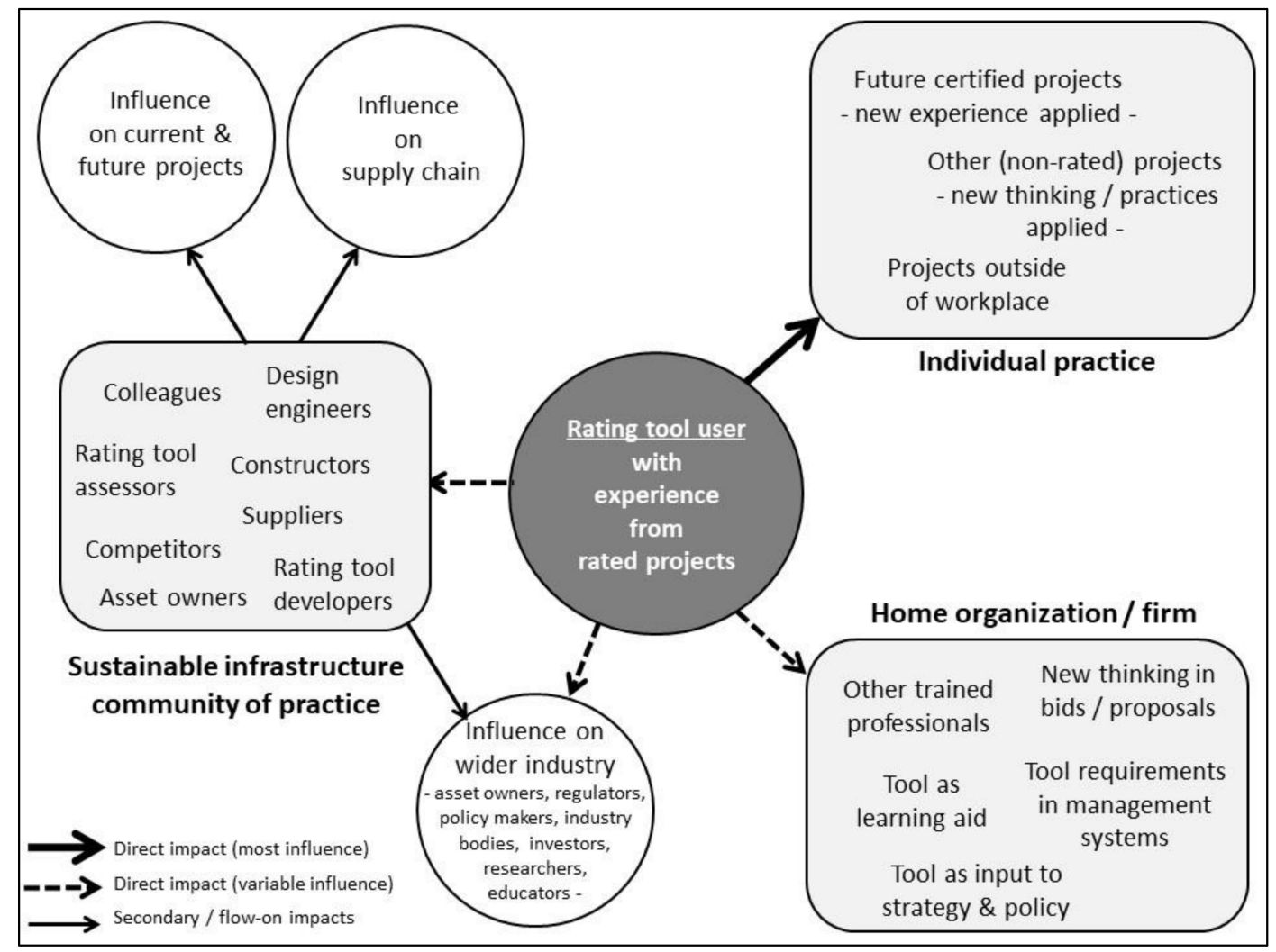

Figure 3. Influence of rating tool user experience beyond their early rated projects.

Individual user experience also brings knowledge of the tools into the organizational context. The study findings showed that the tools are applied within infrastructure owner organizations and construction firms at least to promote sustainability thinking, increase knowledge and capability, influence policy, and embed sustainability practices into project and asset management systems. The findings also indicate an opportunity to drive stronger change in design firms, and further research into the reasons behind the differences in tool influence between firm types would be valuable, particularly as early consideration of sustainability factors in asset design is critical to truly integrated sustainability outcomes [11,27].

\section{Conclusions}

The study findings conclude that the rating tools do spread sustainability knowledge and practices amongst those individuals who use tools on projects, across the communities they participate in, and within the organizations they work for. The impacts of the infrastructure sustainability rating tools are not limited to the projects that undergo rating and certification (i.e., formal use) but extend across the infrastructure industry via informal use and influence at an individual, organizational, and industry level (Figure 4). As Harré suggests [39] (p. 50), "the more that sustainable practices are in the air, the more salient they become and the more likely individual people and groups of people (organizations, city councils, nations) are to replicate them." 


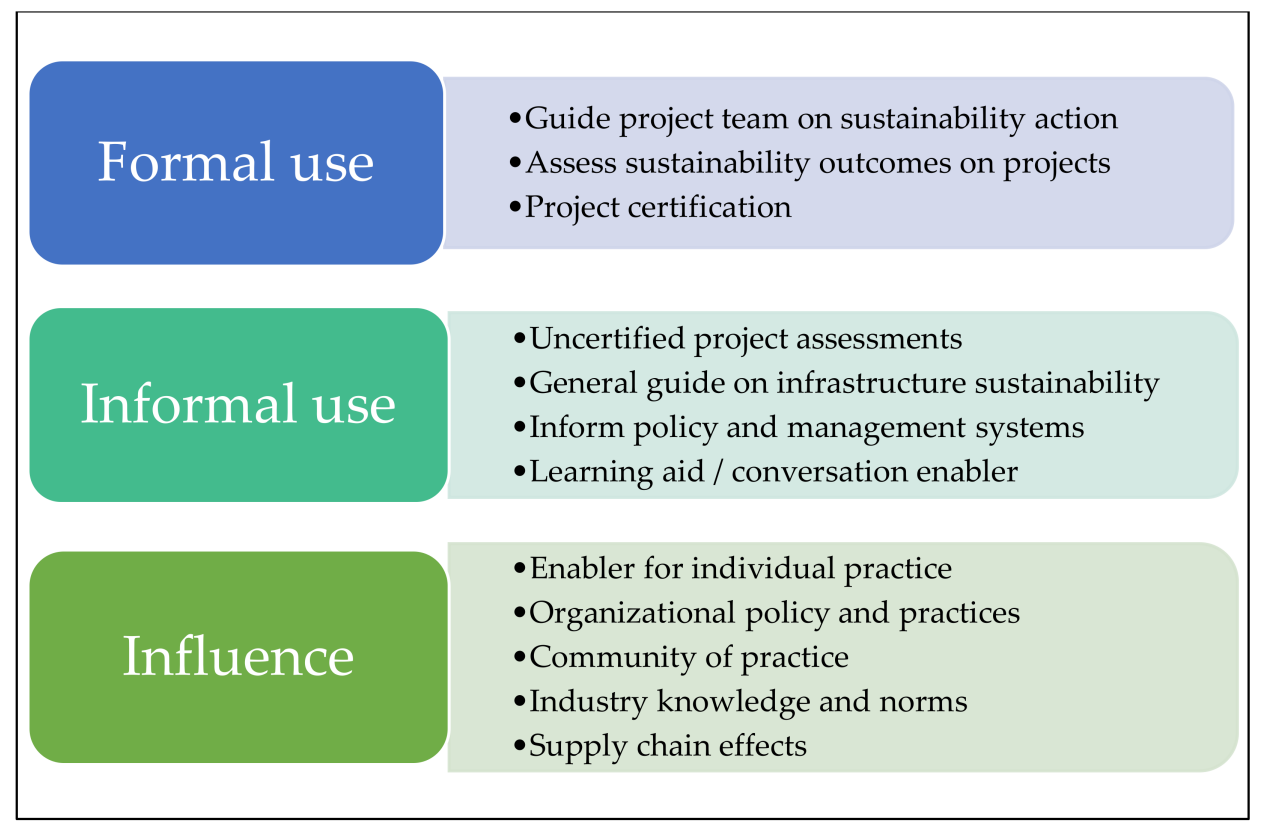

Figure 4. Multiple levels of rating tool impact

While the findings of this study can only be attributed to the 63 research participants, the strength of the results in terms of non-certified use and individual impacts clearly indicate the extended influence of the rating tools in creating a culture in the infrastructure industry oriented to new ways of thinking and behaving. The rating tools are designed as a mechanism for industry players to prescribe, encourage, measure, and promote sustainability practices and outcomes for civil infrastructure projects and assets, but if we limit our thinking about the value of the rating tools to their impacts on certified projects alone we underestimate the opportunity they present. The study concludes that use of the infrastructure sustainability rating tools does "create a climate of sustainability awareness-and of continuous improvement-in the profession and industry" and intelligent use of the tools will accelerate the action needed to address the sustainability challenges we collectively face. Infrastructure owners, design and construction firms, and industry bodies are encouraged to more explicitly recognize the behavior change aspects of rating tool use when developing their sustainability strategies and plans and to look for ways to maximize the value the tools deliver across the formal, informal, and influencing spectrum.

The infrastructure industry must respond to the magnitude and urgency of the sustainability challenges faced by society today and this study demonstrates that the infrastructure sustainability rating tools can play an important role in supporting the industry to address that need. To sustain that role the rating tools must continue to adequately address the sustainability issues relevant to civil infrastructure and evolve to incorporate new knowledge and technologies.

Study findings related to both the influence of rating tool use within design firms and the perceived step change in industry in relation to sustainability could be strengthened through further investigation.

Acknowledgments: The authors would like to acknowledge the 63 infrastructure owners and tool users who so generously made themselves available for interviews, and the tool developers and other contacts who invited their networks to participate in the research.

Author Contributions: Kerry Griffiths conceived and designed the methodology with review and comment from Carol Boyle and Theunis F. P. Henning. Kerry Griffiths undertook the interviews and analyzed the results. Carol Boyle and Theunis F. P. Henning participated in a workshop to review the analysis and provide challenge and feedback. Kerry Griffiths wrote the paper and Carol Boyle and Theunis F. P. Henning provided multiple reviews and comments which are reflected in the final paper.

Conflicts of Interest: The authors declare no conflict of interest. 


\section{Appendix A}

\section{Interview Questions}

Experienced Users-questions relevant to rating tool influence outside of certification of projects

Have you also used the rating schemes in non-certified ways on infrastructure projects? If yes, please describe. Please rate how the use of these tools has influenced your own practice on infrastructure projects (on a scale of 1-5)? 1 = no influence, 5 = extremely influential

Please describe what has changed.

Please rate how the use of these tools has influenced your organization's practices on infrastructure projects (on a scale of 1-5)? 1 = no influence, 5 = extremely influential

Please describe what has changed or has been put in place as a result.

Is there anything else you wish to add that would help us understand your use of the sustainability rating tools and/or their contribution to sustainable infrastructure?

Infrastructure Owners—questions relevant to rating tool influence outside of certification of projects

Do you also use these rating schemes in non-certified ways on infrastructure projects? If yes, please describe. Is there anything else you wish to add that would help us understand your use of the sustainability rating tools and/or their contribution to sustainable infrastructure?

\section{Codebook Example}

\begin{tabular}{ll}
\hline Node Name & Description \\
\hline i. Individual or personal & $\begin{array}{l}\text { How has using the tools affected a person's own practice-either } \\
\text { at a professional level or personal level }\end{array}$ \\
\hline
\end{tabular}

- Enhanced sustainability knowledge

Comments related to the tools having broadened or enhanced knowledge, thinking, and practice in terms of sustainability.

- Confidence and credibility

Comments on the tools giving confidence-because industry endorsed in some way; no longer a passionate individual conversation.

- Community of practice Comments on the value of networking and the community of practice.

- Impact on role

Comments on how the emergence and use of the tools has affected a person's role at work; sometimes role has emerged out of tool use.

- Communication

Comments related to improved ability to communicate on sustainability; tools providing a vehicle for sustainability conversations.

- $\quad$ Beyond work influence

Comments related to impacts beyond the workplace (e.g., at home; renovations, etc.).

Approval to undertake the study interviews was given by the University of Auckland, Human Participants Ethics Committee on 25 August 2015. Reference Number 015026.

\section{References}

1. McKinsey Global Institute. Infrastructure Productivity: How to Save $\$ 1$ Trillion a Year. Available online: https:/ / www.mckinsey.com/industries / capital-projects-and-infrastructure/ our-insights/infrastructureproductivity (accessed on 31 March 2018).

2. FIDIC. State of the World: FIDIC Infrastructure Report; FIDIC: Geneva, Switzerland, 2009. 
3. Boyle, C.; Head, P.; Hood, D.; Lawton, M.; Lowe, I.; O’Connor, M.; Peet, J.; Schreier, H.; Vanegas, J.A. Transitioning to Sustainability: Pathways, Directions and Opportunities. Int. J. Sustain. Dev. 2013, 16, 166-189. [CrossRef]

4. New Climate Economy. The Sustainable Infrastructure Imperative: Financing for Better Growth and Development; New Climate Economy: Washington, DC, USA, 2016.

5. Müller, D.B.; Liu, G.; Løvik, A.N.; Modaresi, R.; Pauliuk, S.; Steinhoff, F.S.; Brattebø, H. Carbon Emissions of Infrastructure Development. Environ. Sci. Technol. 2013, 47, 11739-11746. [CrossRef] [PubMed]

6. Willetts, R.; Burdon, J.; Glass, J.; Frost, M. Fostering Sustainability in Infrastructure Development Schemes. Proc. Inst. Civ. Eng. Eng. Sustain. 2010, 163, 159-166. [CrossRef]

7. Mulligan, C.N. Evaluating Progress on Sustainable Infrastructure. In Proceedings of the CSCE 2011 General Conference, Ottawa, ON, Canada, 14-17 June 2011; pp. 845-855.

8. Berardi, U. Sustainability Assessment of Urban Communities through Rating Systems. Environ. Dev. Sustain. 2013, 15, 1573-1591. [CrossRef]

9. Corvellec, H.; Zapata Campos, M.J.; Zapata, P. Infrastructures, Lock-in, and Sustainable Urban Development: The Case of Waste Incineration in the Göteborg Metropolitan Area. J. Clean. Prod. 2013, 50, 32-39. [CrossRef]

10. Griffiths, K. Sustainability Considerations in Infrastructure Procurement. In Proceedings of the IPWEA NZ 2014: Leading Tomorrow's Infrastructure, Auckland, New Zealand, 26-28 June 2014.

11. Fenner, R.A.; Ryce, T. A Comparative Analysis of Two Building Rating Systems. Part I: Evaluation. Proc. Inst. Civ. Eng. Eng. Sustain. 2008, 161, 55-63. [CrossRef]

12. Conte, E.; Monno, V. Beyond the Building Centric Approach: A Vision for an Integrated Evaluation of Sustainable Buildings. Environ. Impact Assess. Rev. 2012, 34, 31-40. [CrossRef]

13. Ahn, Y.H.; Pearce, A.R.; Wang, Y.; Wang, G. Drivers and Barriers of Sustainable Design and Construction: The Perception of Green Building Experience. Int. J. Sustain. Build. Technol. Urban Dev. 2013, 4, 35-45. [CrossRef]

14. Dasgupta, S.; Tam, E.K.L. Indicators and Framework for Assessing Sustainable Infrastructure. Can. J. Civ. Eng. 2005, 32, 30-44. [CrossRef]

15. Georgoulias, A.; Allen, J.; Farley, L.; Kao, J.K.; Mladenova, I. Towards the Development of a Rating System for Sustainable Infrastructure: A Checklist Or a Decision-Making Tool? In Cities of the Future/Urban River Restoration; Water Environment Federation: Alexandria, VA, USA, 2010; pp. 379-391.

16. Poveda, C.A.; Lipsett, M.G. A Review of Sustainability Assessment and Sustainability/Environmental Rating Systems and Credit Weighting Tools. J. Sustain. Dev. 2011, 4, 36. [CrossRef]

17. CEEQUAL Ltd. CEEQUAL Version 5.1, Assessment Manual for Projects, International Version; CEEQUAL Ltd.: Watford, UK, 2013.

18. Muench, S.; Anderson, J.; Hatfield, J.; Koester, J.; Söderlund, M. Greenroads Manual V1.5; University of Washington: Seattle, WA, USA, 2011.

19. Institute for Sustainable Infrastructure. Envision Rating System for Sustainable Infrastructure; Institute for Sustainable Infrastructure: Washington, DC, USA, 2015.

20. Infrastructure Sustainability Council of Australia (ISCA). Infrastructure Sustainability Rating Tool Technical Manual, Version 1.0; ISCA: Sydney, Australia, 2013.

21. ISCA. The Infrastructure Sustainability Council of Australia. Available online: www.isca.org.au (accessed on 31 March 2018).

22. Institute for Sustainable Infrastructure. Available online: www.sustainableinfrastructure.org (accessed on 31 March 2018).

23. Greenroads International. Available online: www.greenroads.org (accessed on 31 March 2018).

24. CEEQUAL Ltd. Available online: www.ceequal.com (accessed on 31 March 2018).

25. Scanlon, J.; Davis, A. The Role of Sustainability Advisers in Developing Sustainability Outcomes for an Infrastructure Project: Lessons from the Australian Urban Rail Sector. Impact Assess. Proj. Apprais. 2011, 29, 121-132. [CrossRef]

26. Guthrie, P.M.; Konaris, T. State of the World Report 2012: Sustainable Infrastructure; FIDIC: Geneva, Switzerland, 2012.

27. Anderson, J. Measuring Sustainability in Civil Engineering: Development, Testing and Implementation of the Greenroads Rating System; University of Washington: Seattle, WA, USA, 2012. 
28. Muench, S.; Scarsella, M.; Bradway, M.; Hormann, L.; Cornell, L. Evaluating Project-Based Roadway Sustainability Rating System for Public Agency Use. Transp. Res. Rec. 2012, 2285, 8-18. [CrossRef]

29. MacAskill, K.; Guthrie, P.M. Risk-Based Approaches to Sustainability in Civil Engineering. Proc. Inst. Civ. Eng. Eng. Sustain. 2013, 166, 181-190. [CrossRef]

30. Ainger, C.M.; Fenner, R.A. Sustainable Infrastructure: Principles into Practice; ICE Publishing: London, UK, 2014.

31. Pearce, A.R.; Vanegas, J.A. A Parametric Review of the Built Environment Sustainability Literature. Int. J. Environ. Technol. Manage. 2002, 2, 54-93. [CrossRef]

32. Bartke, S.; Schwarze, R. No Perfect Tools: Trade-Offs of Sustainability Principles and User Requirements in Designing Support Tools for Land-use Decisions between Greenfields and Brownfields. J. Environ. Manag. 2015, 153, 11-24. [CrossRef] [PubMed]

33. Fenner, R.A.; Ainger, C.M.; Cruickshank, H.; Guthrie, P.M. Discussion: Widening Engineering Horizons: Addressing the Complexity of Sustainable Development. Proc. Inst. Civ. Eng. Eng. Sustain. 2009, 162, 177-178. [CrossRef]

34. Chong, W.K.; Kumar, S.; Haas, C.T.; Beheiry, S.M.A.; Coplen, L.; Oey, M. Understanding and Interpreting Baseline Perceptions of Sustainability in Construction among Civil Engineers in the United States. J. Manag. Eng. 2009, 25, 143-154. [CrossRef]

35. Hwang, B.; Ng, W.J. Project Management Knowledge and Skills for Green Construction: Overcoming Challenges. Int. J. Proj. Manag. 2013, 31, 272-284. [CrossRef]

36. Udawatta, N.; Zuo, J.; Chiveralls, K.; Zillante, G. Attitudinal and Behavioural Approaches to Improving Waste Management on Construction Projects in Australia: Benefits and Limitations. Int. J. Constr. Manag. 2015, 15, 137-147. [CrossRef]

37. Willetts, R.; Burdon, J.; Glass, J.; Frost, M. Corporate Responsibility Practices in Engineering Consultancies. Int. J. Constr. Manag. 2011, 11, 19-35. [CrossRef]

38. Vaillancourt, A.; Rankin, J.; Wilson, B. Assessing the Ability of Integrated Decision-Making to Improve Canadian Municipal Infrastructure Sustainability. In Proceedings of the Annual Conference of the Canadian Society for Civil Engineering 2012: Leadership in Sustainable Infrastructure, Edmonton, AB, Canada, 6-9 June 2012; pp. 3187-3196.

39. Harré, N. Psychology for a Better World: Strategies to Inspire Sustainability; Lulu.com: Auckland, New Zealand, 2011.

40. Lave, J.; Wenger, E. Situated Learning: Legitimate Peripheral Participation; Cambridge University Press: Cambridge, UK, 1991.

41. Rogers, E.M. Diffusion of Preventive Innovations. Addict. Behav. 2002, 27, 989-993. [CrossRef]

42. Prochaska, J.O; DiClemente, C.C. Stages of Change in the Modification of Problem Behaviors. Prog. Behav. Modif. 1992, 28, 183-218. [PubMed]

43. Prochaska, J.O.; DiClemente, C.C.; Norcross, J.C. In Search of how People Change: Applications to Addictive Behaviors. Am. Psychol. 1992, 47, 1102-1114. [CrossRef] [PubMed]

44. Prochaska, J.M.; Prochaska, J.O.; Levesque, D.A. A Transtheoretical Approach to Changing Organizations. Adm. Policy Ment. Health 2001, 28, 247-261. [CrossRef] [PubMed]

45. Abrash Walton, A. Positive Organizational Leadership and Pro-Environmental Behavior: The Phenomenon of Institutional Fossil-Fuel Divestment; Antioch University: Culver City, CA, USA, 2016.

46. Innes, J.E.; Booher, D.E. Indicators for Sustainable Communities: A Strategy Building on Complexity Theory and Distributed Intelligence. Plan. Theory Pract. 2000, 1, 173-186. [CrossRef]

47. Davidson, K.M.; Venning, J. Sustainability Decision-Making Frameworks and the Application of Systems Thinking: An Urban Context. Local Environ. 2011, 16, 213-228. [CrossRef]

48. Capra, F. Complexity and Life. Syst. Res. Behav. Sci. 2007, 24, 475-479. [CrossRef]

49. CEEQUAL Ltd. Scheme Description, CEEQUAL for Projects (Version 5); CEEQUAL Ltd.: Watford, UK, 2012.

50. Boeije, H. A Purposeful Approach to the Constant Comparative Method in the Analysis of Qualitative Interviews. Qual. Quant. 2002, 36, 391-409. [CrossRef]

51. Gagnon, B.; Leduc, R.; Savard, L. From a Conventional to a Sustainable Engineering Design Process: Different Shades of Sustainability. J. Eng. Des. 2012, 23, 49-74. [CrossRef]

52. Tsai, C.Y.; Chang, A.S. Framework for Developing Construction Sustainability Items: The Example of Highway Design. J. Clean. Prod. 2012, 20, 127-136. [CrossRef] 
53. Westley, F.; Olsson, P.; Folke, C.; Homer-Dixon, T.; Vredenburg, H.; Loorbach, D.; Thompson, J.; Nilsson, M.; Lambin, E.; Sendzimir, J. Tipping Toward Sustainability: Emerging Pathways of Transformation. AMBIO 2011, 40, 762-780. [CrossRef] [PubMed]

54. Geels, F.W. A Socio-Technical Analysis of Low-Carbon Transitions: Introducing the Multi-Level Perspective into Transport Studies. J. Transp. Geogr. 2012, 24, 471-482. [CrossRef] 